\title{
Dynamin inhibitors impair platelet-derived growth factor $\beta$-receptor dimerization and signaling
}

\author{
Johan Heldin*, Marie Rubin Sander, Mattias Leino, Sara Thomsson, Johan Lennartsson, \\ Ola Söderberg
}

Department of Pharmaceutical Biosciences, Uppsala University, Uppsala, Sweden

A R T I C L E I N F O

\section{Keywords:}

RTK signaling

EGFR

PDGFR- $\beta$

Dynasore

Dyngo

Dimerization

\begin{abstract}
A B S T R A C T
The role of plasma membrane composition and dynamics in the activation process of receptor tyrosine kinases (RTKs) is still poorly understood. In this study we have investigated how signaling via the RTK, platelet-derived growth factor $\beta$-receptor (PDGFR- $\beta$ ) is affected by Dynasore or Dyngo-4a, which are commonly used dynamin inhibitors. PDGFR- $\beta$ preferentially internalizes via clathrin-coated pits and in this pathway, Dynamin II has a major role in the formation and release of vesicles from the plasma membrane by performing the membrane scission. We have found that dynamin inhibitors impedes the activation of PDGFR- $\beta$ by impairing ligand-induced dimerization of the receptor monomers, which leads to a subsequent lack of phosphorylation and activation both of receptors and downstream effectors, such as ERK1/2 and AKT. In contrast, dynamin inhibitors did not affect epidermal growth factor receptor (EGFR) dimerization and phosphorylation. Our findings suggest that there is a link between plasma membrane dynamics and PDGFR- $\beta$ activation, and that this link is not shared with the epidermal growth factor receptor.
\end{abstract}

\section{Introduction}

The receptor tyrosine kinase (RTK) family consists of 20 subfamilies with a total of 58 members, which have important functions, e.g., in embryogenesis, angiogenesis and tissue homeostasis [1]. All RTKs consist of an extracellular ligand-binding domain that is connected to the intracellular kinase domain by a single transmembrane domain [1]. Upon binding of ligand, many RTKs dimerize; first, the extracellular domains are brought together, which induces a conformational change in the intracellular part of the receptor, thus enabling subsequent phosphorylation at specific tyrosine residues in the cytoplasmic domain $[2,3]$. This enhances the activity of the receptor kinase domain and attracts SH2-domain-containing proteins that bind to specific phosphorylated tyrosine residues in the receptor and initiate down-stream signal transduction [1,2]. Following activation, receptors are internalized. This is important for activation of specific down-stream pathways, like small RhoGTPase Rac1 and ERK1/2 MAP-kinase, which are both activated in endosomal compartments [4,5]. PI3K and PLC $\gamma$ signaling on the other hand, are activated at the plasma membrane and not in early endosomes since their substrate phosphatidylinositol-4,5bisphosphate $\left(\mathrm{PI}(4,5) \mathrm{P}_{2}\right)$ is enriched in the plasma membrane, but not in early endosomes [6]. This illustrates the importance of receptor internalization for proper activation of signaling pathways, both qualitatively and quantitatively.

The platelet-derived growth factor (PDGF) family of isoforms consists of the homo-dimers PDGF-AA, -BB, -CC, -DD and the hetero-dimer PDGF-AB. They bind to and form homo- or hetero-dimers of the $\alpha$ (PDGFR- $\alpha$ ) and $\beta$ - (PDGFR- $\beta$ ) isoforms of the PDGF receptors [2]. PDGFR- $\beta$ is mainly expressed on mural cells and has been shown to be important for maturation of the vasculature by recruiting pericytes to the newly formed sprouts during angiogenesis. Moreover, PDGFR- $\beta$ has been implicated as a major regulator of tissue homeostasis and extracellular fluid pressure by regulating contractility of fibroblasts in the extracellular matrix [2,7].

After ligand-induced activation, PDGFR- $\beta$ is internalized primarily through clathrin-coated pits [2,3]. The pits are decorated at the outer edges with large GTPases of the Dynamin family, which consists of Dynamin I, II and III [5,8]. Dynamin I and III are predominantly expressed in brain and testis, respectively, whereas Dynamin II is ubiquitously expressed [5]. Dynamin II stabilizes the clathrin-coated pits and is important for their formation by starting the invagination of the plasma membrane [9] and it also conducts the final step by performing

\footnotetext{
Abbreviations: PDGFR- $\beta$, platelet-derived growth factor $\beta$-receptor; EGFR, epidermal growth factor receptor; Tyr751, tyrosine 751; PLA, proximity ligation assay

* Corresponding author.

E-mail address: johan.heldin@farmbio.uu.se (J. Heldin).
} 
the final scission that releases the vesicle from the plasma membrane $[10,11]$. The released PDGFR- $\beta$ containing vesicle then fuses with endosomes, there it can be recycled back to the plasma membrane or sorted toward the lysosome where the receptor is degraded [2].

Dynamin is a large GTPase that is inactive in its GDP-bound state and is activated by displacement of GDP, which permits GTP to bind. Compared to small GTPases that are regulated in the same manner, Dynamin has a higher intrinsic GTPase activity than small GTPases $[8,12]$, and is organized in self-assembled oligomers that form a circle or a spiral in $\mathrm{PI}(4,5) \mathrm{P}_{2}$-rich domains [8]; GTPase hydrolysis is linked to the conformational change that contracts the circle, thus making the clathrin-coated pit smaller and forcing it to invaginate and finally release from the plasma membrane [12]. There are several inhibitors of internalization, among them Dynasore and Dyngo-4a, which are low molecular weight non-competitive inhibitors of the GTPase activity of Dynamin I and II [9,13]. Dyngo-4a is more specific towards helical Dynamin II oligomers which are mainly found at the vesicle neck connected to the plasma membrane, whereas Dynasore inhibits both helical and circular oligomers [13]. However, as with most low molecular weight inhibitors there have been reports of additional effects in response to Dynasore in Dynamin I-III triple knock-out mouse fibroblasts [14].

In the present study, we show that dynamin inhibitors impairs dimerization and phosphorylation of PDGFR- $\beta$, whereas EGFR dimerization and phosphorylation is not significantly affected, suggesting that these two RTKs have different requirements for their activation. Thus, we propose a link between membrane invagination driven by Dynamin II and PDGFR- $\beta$ kinase activation.

\section{Materials and methods}

\subsection{Cell culture}

The immortalized human foreskin fibroblast cell line BJ-hTERT (kind gift from Tarjei Mikkelsen, Broad Institute, MIT) and the primary human lung fibroblast cell line HFL1 (kind gift from Pär Gerwins, Uppsala University), were cultured at $37^{\circ} \mathrm{C}$ and $5 \% \mathrm{CO}_{2}$ in Dulbecco's modified Eagle's medium + Glutamax (DMEM + Glutamax), supplemented with $10 \%$ fetal bovine serum (FBS) (all from Thermo Fisher Scientific).

\section{2. siRNA transfection}

BJ-hTERT cells were seeded in an 12-well tissue culture plate at a confluency of 50000 cells $/ \mathrm{cm}^{2}$. While adhering, the cells were transfected with $50 \mathrm{nM}$ siRNA targeting Dynamin II (s4212) using Lipofectamine $^{\mathrm{TM}} 3000$ Transfection Reagent according to the recommendations by the manufacturer (all from Thermo Fisher Scientific).

\subsection{Western blot}

Stimulations were done essentially as described in Ref. [15]. Briefly, BJ-hTERT cells were transferred to a cell culture plate (50000 cells/ $\mathrm{cm}^{2}$ ) and let to adhere and spread overnight (ON), thereafter the cells were starved ON in DMEM + Glutamax, supplemented with $0.2 \%$ FBS (starvation medium). All ligands and inhibitors were equilibrated in starvation medium for $10 \mathrm{~min}$ at $37{ }^{\circ} \mathrm{C}$ before use. The cells were incubated with $80 \mu \mathrm{M}$ Dynasore, $30 \mu \mathrm{M}$ Dyngo-4a or equal volume DMSO for $1 \mathrm{~h}$ and $45 \mathrm{~min}$ and stimulated with either $50 \mathrm{ng} / \mathrm{mL}$ PDGF-BB or $30 \mathrm{ng} / \mathrm{mL} \mathrm{EGF}$ at $37^{\circ} \mathrm{C}$ or on ice for the last $5,15,30,45$ or $60 \mathrm{~min}$, as indicated. The stimulation on ice was preceded by a $10 \mathrm{~min}$ preincubation on ice. For ligand-dependent or -independent activation of PDGFR- $\beta$, treatments with $50 \mathrm{ng} / \mathrm{mL}$ PDGF-BB or $100 \mu \mathrm{M}$ pervanadate for $5 \mathrm{~min}$ at $37^{\circ} \mathrm{C}$, were performed. Following the specified treatments, cells were briefly washed in ice-cold PBS on ice and lysed in
$2 \times$ NuPAGE $^{\mathrm{TM}}$ LDS Sample Buffer supplemented with $100 \mathrm{mM}$ dithiothreitol (DTT) (Sample buffer). Samples were denatured at $95^{\circ} \mathrm{C}$ for 5 min before being subjected to SDS-polyacrylamide gel electrophoresis and subsequently transferred to a PVDF membrane using Iblot2. Before transfer, the gels were soaked in semidry transfer buffer (50 mM Tris base, $40 \mathrm{mM}$ glycine, $0.037 \%$ SDS and $20 \%$ methanol) for $10 \mathrm{~min}$ to better facilitate the transfer of large proteins. Chameleon Duo (Li-core) was used as a molecular size marker. Membranes were blocked with Odyssey blocking buffer (LI-COR Biosciences, diluted 1:3 in TBS) for $2 \mathrm{~h}$ before being incubated $\mathrm{ON}$ at $4{ }^{\circ} \mathrm{C}$ with primary antibodies; rabbit antiPDGFR- $\beta$ (\#3169, Cell Signaling Technology) at 1:1000, goat antiPDGFR- $\beta$ (AF385, RnD Systems) at $1 \mu \mathrm{g} / \mathrm{mL}$, mouse anti-pY751-PDGFR$\beta$ (\#3166, Cell Signaling Technology) at 1:1000, rabbit anti-pY857PDGFR- $\beta$ (\#3170, Cell Signaling Technology) at 1:1000, rabbit antipY1068-EGFR (\#3777, Cell Signaling Technology) at 1:1000, mouse anti-EGFR (MS-665-P1ABX, Fisher scientific) at $1 \mu \mathrm{g} / \mathrm{mL}$, mouse antiAKT (\#2920, Cell Signaling Technology) at 1:500, rabbit anti-pAKT (\#4060, Cell Signaling Technology) at 1:500, $\beta$-actin (sc-47778, Santa Cruz Biotechnology) at 1:1000 and rabbit anti-p ERK1/2 (\#9101, Cell Signaling Technology) at 1:1000. Membranes were washed $3 \times 10 \mathrm{~min}$ in $0.05 \%$ Tween-20 in TBS and incubated with the appropriate fluorescently tagged secondary antibodies (Alexa680 and IRDye800) diluted in blocking buffer. The membranes were then washed in $0.05 \%$ Tween20 in TBS for $3 \times 10 \mathrm{~min}$ and finally in TBS for $10 \mathrm{~min}$. All membranes were scanned using an Odyssey Scanner and the blots were quantified using ImageStudio Lite v5.2.5 (LI-COR Biosciences).

\subsection{Dimerization assay}

After stimulation with $50 \mathrm{ng} / \mathrm{mL}$ PDGF-BB for $5 \mathrm{~min}$ at $37^{\circ} \mathrm{C} \mathrm{BJ}$ hTERT cells were washed three times on ice with ice-cold PBS. Thereafter the cells were incubated on ice with $2 \mathrm{mM}$ bis-sulfosuccinimidyl suberate (BS3, Thermo Fisher Scientific, 21,580) in ice-cold PBS for $60 \mathrm{~min}$. The crosslinking was terminated by washing three times $5 \mathrm{~min}$ in $100 \mathrm{mM}$ Tris (pH 7.5) in PBS. Thereafter the cells were lysed and subjected to SDS-polyacrylamide gel electrophoresis as described above, and the proteins in the gel were transferred using wet transfer over night at $30 \mathrm{~V}$ (transfer buffer: $25 \mathrm{mM}$ Tris base, $192 \mathrm{mM}$ glycine and $20 \%$ methanol).

\subsection{Biotinylation of cell surface proteins}

The biotinylation of cell surface proteins was done essentially as described for the dimerization assay, however, instead of $2 \mathrm{mM}$ bissulfosuccinimidyl suberate (BS3), $2 \mathrm{mM}$ EZ-Link ${ }^{\mathrm{TM}}$ Sulfo-NHS-Biotin (Thermo Fisher Scientific, 21,217), was used. The cells were lysed in IP lysis buffer (20 mM Tris HCl, pH 8.0, $137 \mathrm{mM} \mathrm{NaCl}, 10 \%$ glycerol, 1\% nonidet P-40 and 2 mM EDTA), supplemented with PhosSTOP (Sigma, 04906837 001) and cOmplete Tablets (Sigma, 04693124 001), cleared by centrifugation and incubated with Streptavidin Magnetic Sepharose beads (vwr, 28-9857-38) for $2 \mathrm{~h}$, end-over-end at $4{ }^{\circ} \mathrm{C}$ to pull down biotinylated cell surface proteins. The beads were then washed three times in lysis buffer and finally proteins were desorbed with sample buffer.

\subsection{Immunocytochemistry}

The stimulations and preincubations were done as described above. Briefly, the cells were seeded in 8-well chamber slides (50 000 cells/ $\mathrm{cm}^{2}$ ) and incubated ON to enable the cells to adhere and spread. The cells were thereafter starved ON before being incubated and stimulated with $50 \mathrm{ng} / \mathrm{mL}$ PDGF-BB, as indicated. The stimulation was stopped by washing once in ice-cold PBS; thereafter, the cells were fixed in $10 \%$ formalin diluted in PBS (3.7\% PFA and 1\% methanol in PBS) for $15 \mathrm{~min}$ on ice. The cells were washed $3 \times 5 \mathrm{~min}$ and finally the wells were removed and the slide dried. The wells were encircled with a 
A

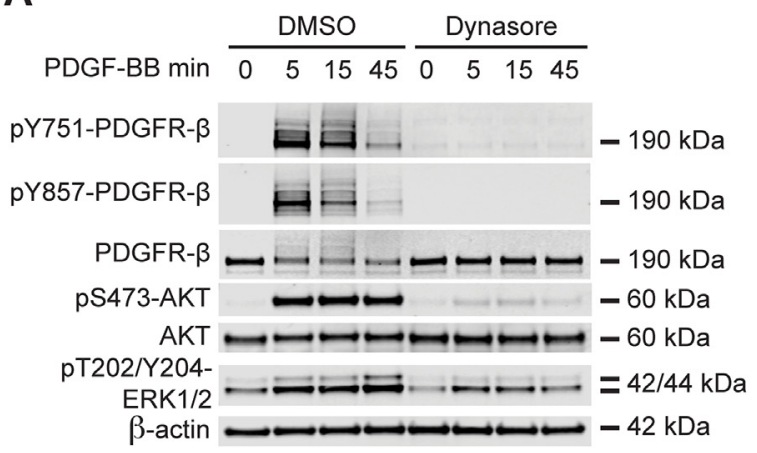

B

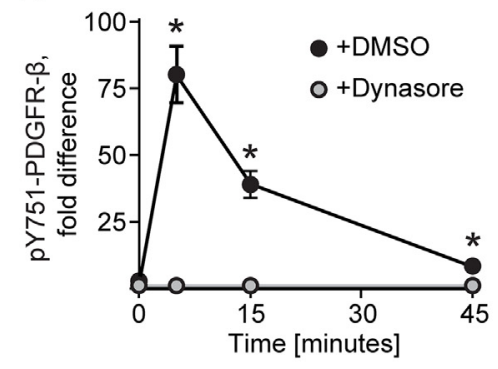

C

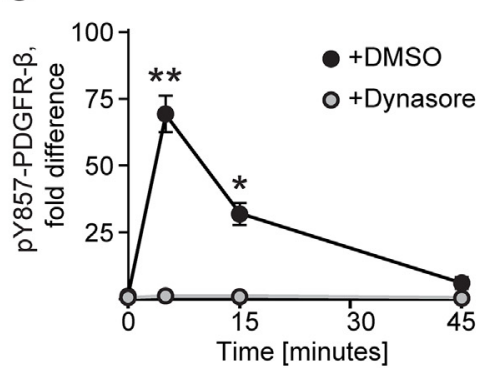

F

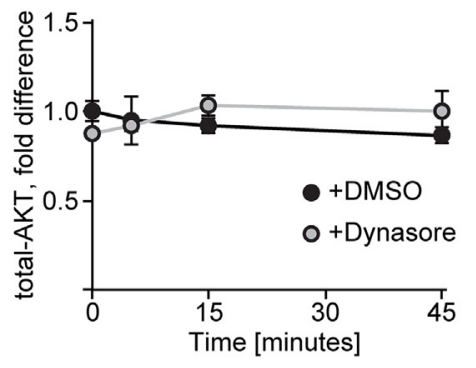

$D_{8}$

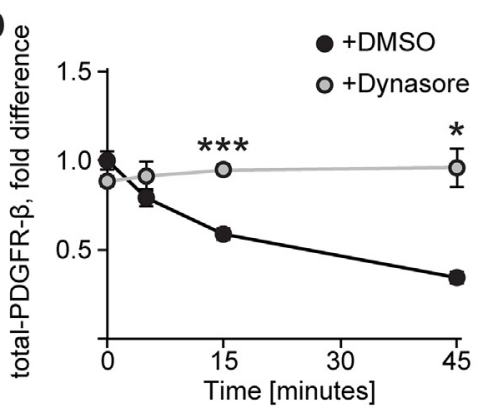

G

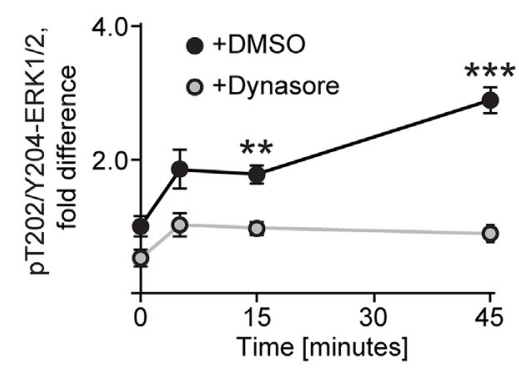

E

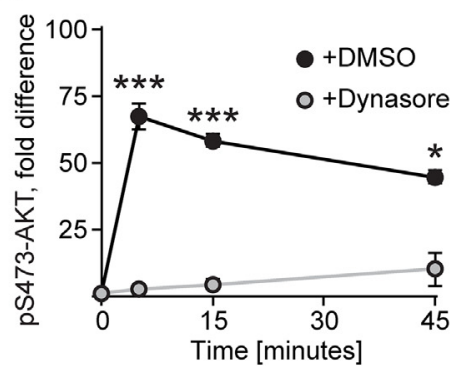

H

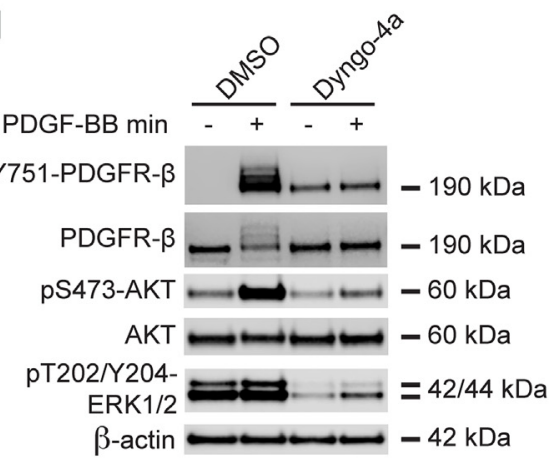

L $\quad$-DMSO

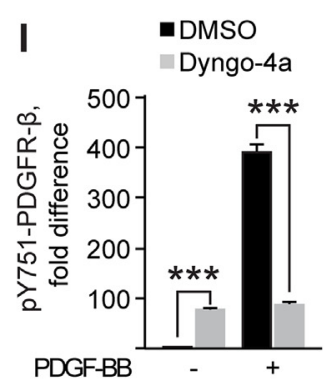

$\mathbf{J} \quad \begin{aligned} & \text { DMSO } \\ & \text { Dyngo-4a }\end{aligned}$
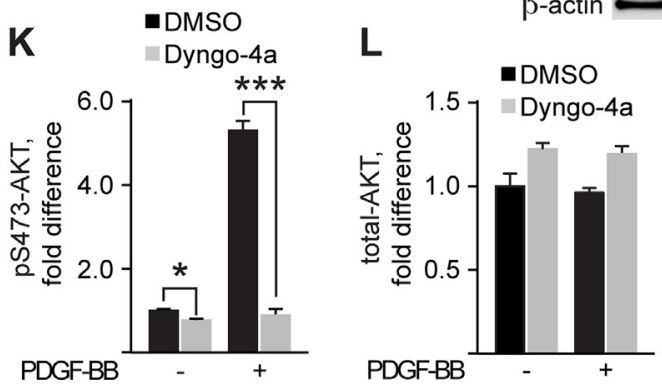

PDGF-BB

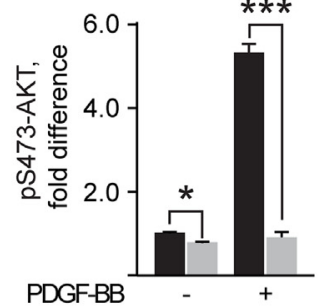

PDGF-BB

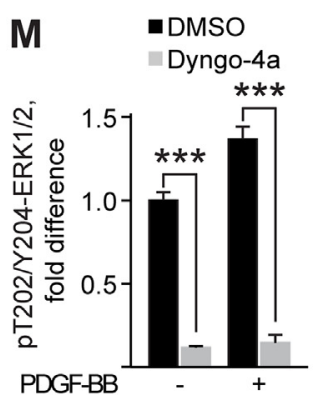

$\mathbf{N}$

Streptavidin Pulldown

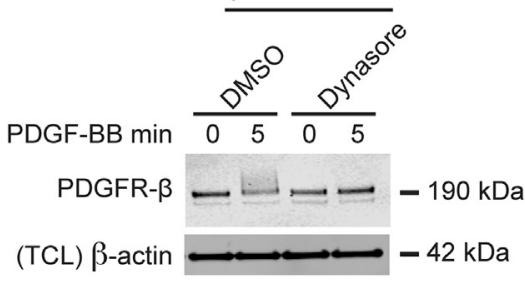

(caption on next page) 


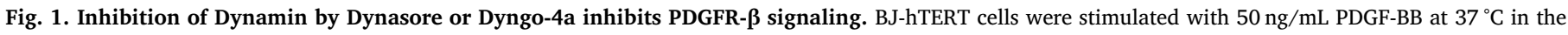

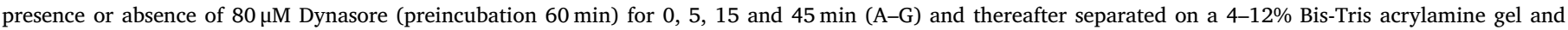

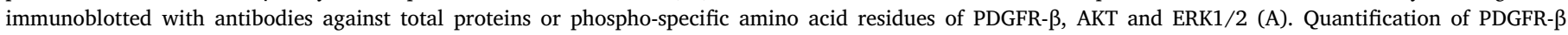

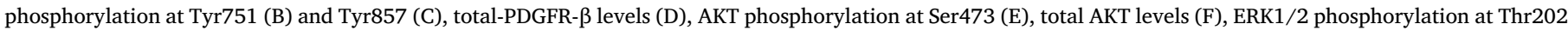

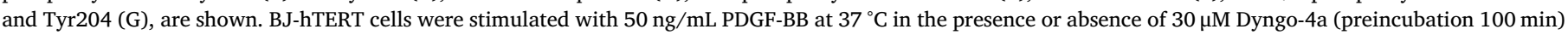

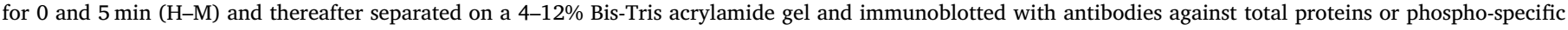

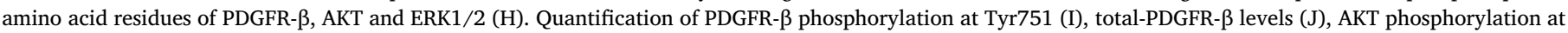

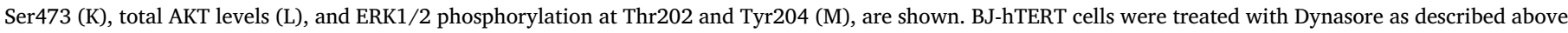

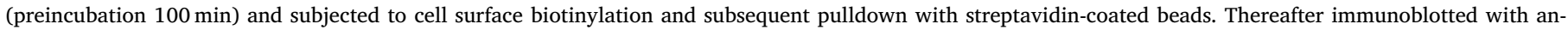

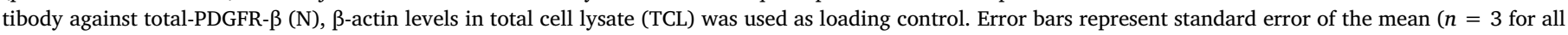
experiments), ${ }^{*}=\mathrm{p}<0.05,{ }^{* *}=\mathrm{p}<0.01,{ }^{* * *}=\mathrm{p}<0.005$.

hydrophobic barrier-pen and rehydrated with TBS, and then permeabilized in $0.2 \%$ Triton X-100 in TBS for $10 \mathrm{~min}$ on an orbital shaker. The slides were briefly rinsed in TBS and blocked in a moisture chamber with Odyssey blocking buffer (LI-COR Biosciences, diluted 1:2 in TBS) for $1 \mathrm{~h}$ at $37^{\circ} \mathrm{C}$. The cells were thereafter incubated $\mathrm{ON}$ at $4{ }^{\circ} \mathrm{C}$ in a moisture chamber with primary antibody targeting PDGFR- $\beta$ (\#3169, Cell Signaling Technology) at 1:100 dilution. The cells were thereafter washed in $0.05 \%$ Tween-20 in TBS for $3 \times 10 \mathrm{~min}$ and incubated in a moisture chamber with Goat anti-Rabbit Alexa Fluor Plus 555 (A32732, Thermo scientific) diluted 1:500 and $40 \mu \mathrm{g} / \mathrm{mL}$ Hoechst 33,342 in PBS for $1 \mathrm{~h}$ at $37^{\circ} \mathrm{C}$. Finally, the slides were washed in $0.05 \%$ Tween-20 in TBS for $3 \times 10 \mathrm{~min}$ and mounted with slowfade Gold antifade mounting reagent (S36936, Thermo Scientific).

\subsection{In situ proximity ligation assay (PLA)}

Stimulations, pre-incubations and procedures until incubations of primary antibodies were done as described above. After incubation with primary antibodies targeting PDGFR- $\beta$ (\#3169, Cell Signaling Technology) at 1:100, goat anti-PDGFR- $\beta$ (AF385, RnD Systems) at $5 \mu \mathrm{g} / \mathrm{mL}$, mouse anti-pY751-PDGFR- $\beta$ (\#3166, Cell Signaling Technology) at 1:200, rabbit anti-Dynamin 2 (ab65556, abcam) at 1:100 or mouse-anti EEA1 (610456, BD transduction laboratories) at $1: 200$, the cells were washed in TBS for $3 \times 10 \mathrm{~min}$ and incubated in a moisture chamber with secondary proximity probes (Duolink probes) targeting the primary antibodies according to manufacturers instructions (Olink bioscience), as described [16]. Thereafter, the cells were washed $3 \times 10 \mathrm{~min}$ in $0.05 \%$ Tween-20 in TBS and hybridization and ligation was performed using Duolink ligation mixture followed by $3 \times 10$ min wash in TBS. Finally, rolling circle amplification was performed for $90 \mathrm{~min}$ using Duolink amplification mixture Red supplemented with $10 \mu \mathrm{g} / \mathrm{mL}$ Hoechst 33,342. The cells were washed $2 \times 10 \mathrm{~min}$ in TBS and finally in 0.3xTBS for $20 \mathrm{~min}$ and then mounted with Slowfade Gold antifade mounting reagent (S36936, Thermo Scientific).

\subsection{Imaging}

For all experiments at least three images were acquired per condition. The microscope used was a Zeiss imager Z2 controlled by the Zen 2 (blue edition) software. All images were taken with a $40 \times / 1.4$ oil objective and a Hamamatsu C11440 camera. The samples were excited by a HXP $120 \mathrm{~V}$ light source (90\% light intensity) and imaged using filter cubes sets 49 and 31 from Zeiss, which are suitable for the fluorescence wavelengths of Hoechst and TexasRed/Alexa Fluor Plus 555. PLA product signal strength has in the figures been enhanced for visualization purposes; however, image analysis has been performed on original images.

\subsection{Image analysis}

Image analysis and quantification were done using the CellProfiler software version 2.2.0, made available by the Broad Institute Imaging Platform [17].

\subsection{Statistical analysis}

All experiments were repeated three or more independent times and two-tailed unpaired Student's $t$-test was employed for statistical analysis. All experiments have been normalized to the mean of the unstimulated and untreated timepoints in each experiment.

\subsection{Antibody and cell validation}

All antibodies were validated using immunoblotting on BJ-hTERT cells. Cells were checked for mycoplasma infection by qPCR when brought into the lab and thereafter routinely checked by staining with Hoechst.

\section{Results}

\subsection{Inhibition of Dynamin impairs PDGFR- $\beta$ but not EGFR signaling}

The main internalization pathway of PDGFR- $\beta$ is through clathrincoated pits. We used the Dynamin inhibitors Dynasore and Dyngo-4a to determine the importance of Dynamin II for activation and pre-internalization signaling of PDGFR- $\beta$, and compared to EGFR. When BJhTERT foreskin fibroblasts were treated with Dynasore, PDGF-BB-induced phosphorylation of PDGFR- $\beta$ was abolished; in contrast, liganddependent autophosphorylation of, e.g., Tyr751 and Tyr857 in PDGFR$\beta$, was seen in control cells (Fig. 1A,B,C). Moreover, PDGFR- $\beta$ was not degraded in the presence of Dynasore (Fig. 1A,D), which probably is a result of Dynamin II's well-documented role in clathrin-mediated internalization. Consistent with a block in receptor phosphorylation, activation of downstream kinases, such as AKT and ERK1/2 MAP-kinase, was impaired. The most pronounced effect was seen for AKT phosphorylation on Ser473, which was almost entirely abolished after Dynasore treatment (Fig. 1A,E,F). Also ERK1/2 phosphorylation at Thr202 and Tyr204 was impaired, but to a lower degree (Fig. 1A,G). These results were corroborated using another Dynamin inhibitor, Dyngo-4a (Fig. 1). Inhibition by Dyngo-4a gave a slight background phosphorylation of PDGFR- $\beta$, but completely abolished the induction of receptor phosphorylation in response to ligand binding (Fig. 1H,I,J). Dyngo-4a also abolished all downstream signaling through AKT and ERK1/2, which is in line with the results seen in response to Dynasore treatment (Fig. 1H,K,L,M). Thus, both Dynasore and Dyngo-4a had the same effect on PDGFR- $\beta$ activation and signaling.

Re-routing of endosomal trafficking has been shown to influence signaling activity of EGFR [18]. Therefore, if recycled, redistributed or newly synthesized PDGFR- $\beta$ were unable to reach the cell surface, this would lead to a subsequent depletion of receptor levels on the plasma membrane, which would prevent PDGF-BB from reaching PDGFR- $\beta$ and thus explain the lack of receptor activation. We therefore investigated if the impaired signaling after Dynasore treatment was due to disturbed localization of the receptor to the plasma membrane. This possibility was investigated by performing biotinylation of cell-surface proteins followed by pulldown by streptavidin-coated beads. We were unable to detect any difference in PDGFR- $\beta$ cell surface levels between control and Dynasore treated cells at the zero timepoint (Fig. 1N). Hence, the 
A

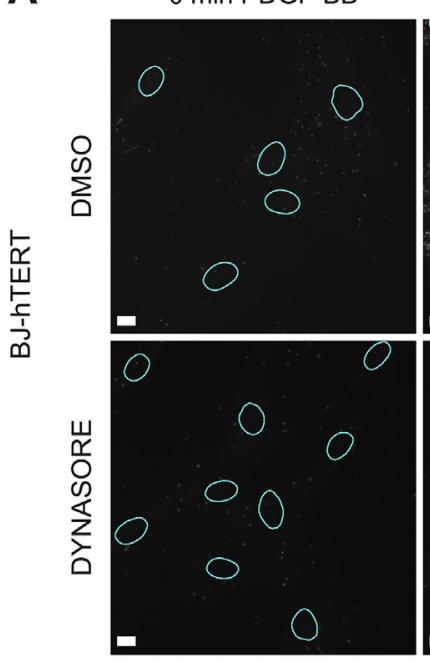

C
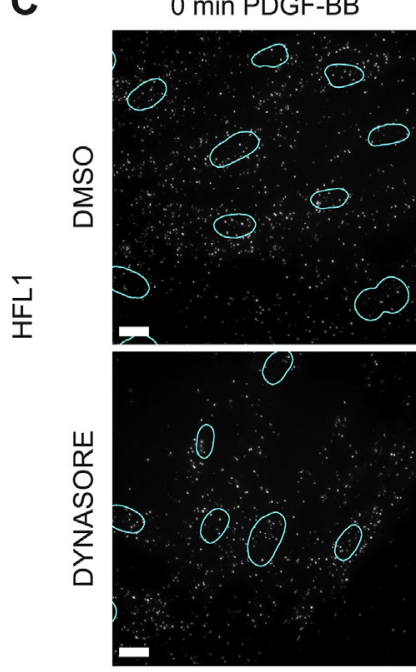

5 min PDGF-BB

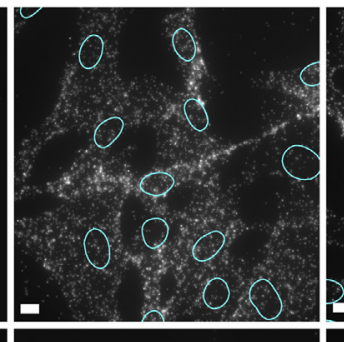

15 min PDGF-BB

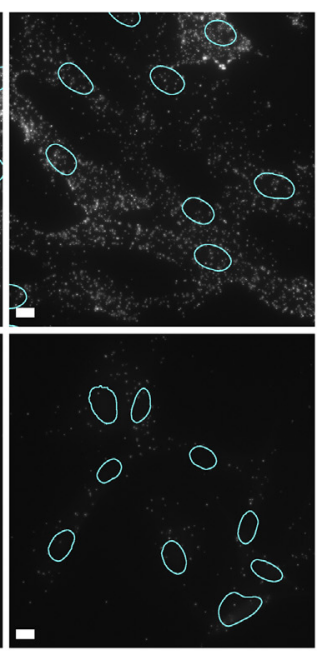

B

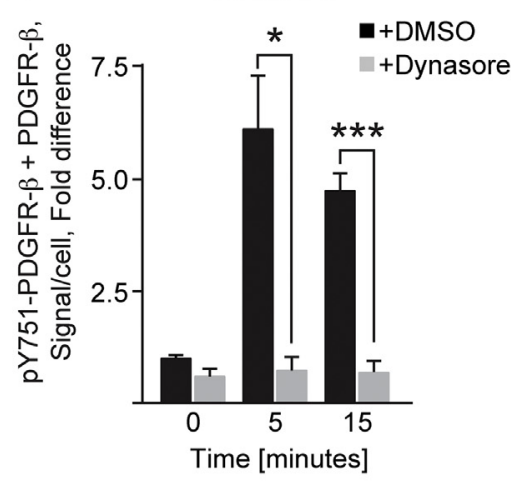

D
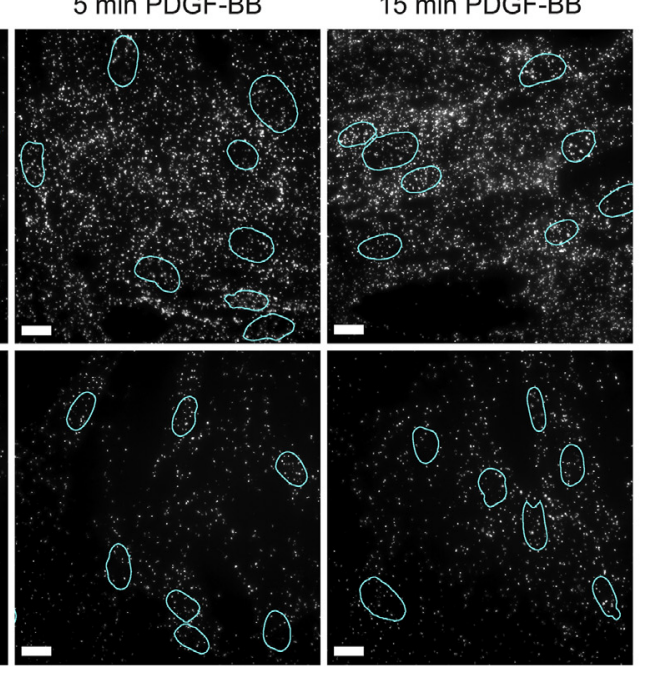

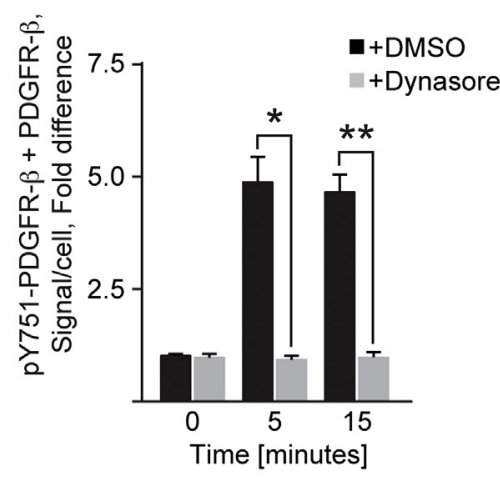

Fig. 2. Dynasore inhibits PDGFR- $\beta$ signaling. BJ-hTERT (A) and HFL1 (C) cells were stimulated with $50 \mathrm{ng} / \mathrm{mL}$ PDGF-BB at $37^{\circ} \mathrm{C}$ in the presence or absence of $80 \mu \mathrm{M}$ Dynasore (preincubation $90 \mathrm{~min}$ ) for 0,5 and $15 \mathrm{~min}$. PDGFR- $\beta$ phosphorylation at Tyr751 (combined with antibody against total-PDGFR- $\beta$ ) was quantified by proximity ligation assay. Representative pictures of cells with PLA products for each condition are shown (A and C), as well as their quantification (B and D, respectively). The nuclei are outlined by a turquoise line. Error bars represent standard error of the mean (Scale bar $=10 \mu \mathrm{m}, n=3$ for all experiments), $*=\mathrm{p}<0.05, * *=\mathrm{p}<0.01, * * *=\mathrm{p}<0.005$.

inhibitory effect of Dynasore on PDGFR- $\beta$ activation is not caused by redistribution of the receptor from the plasma membrane.

As a complement to immunoblotting and to further confirm the effect of Dynasore on PDGFR- $\beta$ activation, we employed proximity ligation assay (PLA) in BJ-hTERT (Fig. 2A and B) and HFL1 (human lung fibroblasts; Fig. 2C and D) cells. This was done using antibodies recognizing phosphorylated tyrosine 751 in PDGFR- $\beta$, and total PDGFR- $\beta$. By investigating the amount of phosphorylation on Tyr751 in PDGFR- $\beta$, we could confirm that Dynasore abolishes PDGFR- $\beta$ activation in both cell lines, consistent with our results using immunoblotting. Interestingly, EGFR signaling (Fig. 3A and B), degradation (Fig. 3A,C) and downstream signaling via AKT and ERK1/2 (Fig. 3A,D,E,F), were not affected by Dynasore treatment. Hence, inhibition by Dynasore has different effects on PDGFR- $\beta$ and EGFR activation.

\subsection{Dynasore regulates PDGFR- $\beta$ internalization and recruitment to clathrin-coated pits}

To investigate PDGFR- $\beta$ localization in BJ-hTERT cells treated with PDGF-BB in the presence or absence of Dynasore, PLA and immunocytochemical staining of PDGFR- $\beta$ were carried out. Instead of the characteristic dot-shaped pattern of PDGFR- $\beta$ usually seen after ligand stimulation, PDGFR- $\beta$ was localized in large structures in Dynasore treated cells, which were unaffected by addition of PDGF-BB (Fig. 4A), suggesting a disturbance of the normal membrane localization of PDGFR- $\beta$. To investigate the localization of PDGFR- $\beta$ closer, PLA was employed. PLA provides the ability to monitor proximal binding of antibodies in fixed cells or tissue sections [19]. A positive PLA signal is only obtained if the distance between the antigens are less than $40 \mathrm{~nm}$. PLA analysis thus allows for a more precise determination of proteinprotein interaction compared to conventional immunocytochemistry (ICC) [20]. Dynasore treatment was found to impair PDGFR- $\beta$ internalization to EEA1-coated early endosomes (Fig. 4B and C), as well as the recruitment of PDGFR- $\beta$ to clathrin-coated pits (Fig. 4D and E), as determined by PLA analyses using an antibody against PDGFR- $\beta$, combined with antibodies against EEA1 or clathrin, respectively. However, Dynasore did not significantly affect the interaction between Dynamin II and PDGFR- $\beta$ (Fig. $4 \mathrm{~F}$ and G). This observation suggests that PDGFR- $\beta$ forms a complex with Dynamin II and that Dynamin II activity is important for the redistribution of PDGFR- $\beta$ into clathrin- 
A
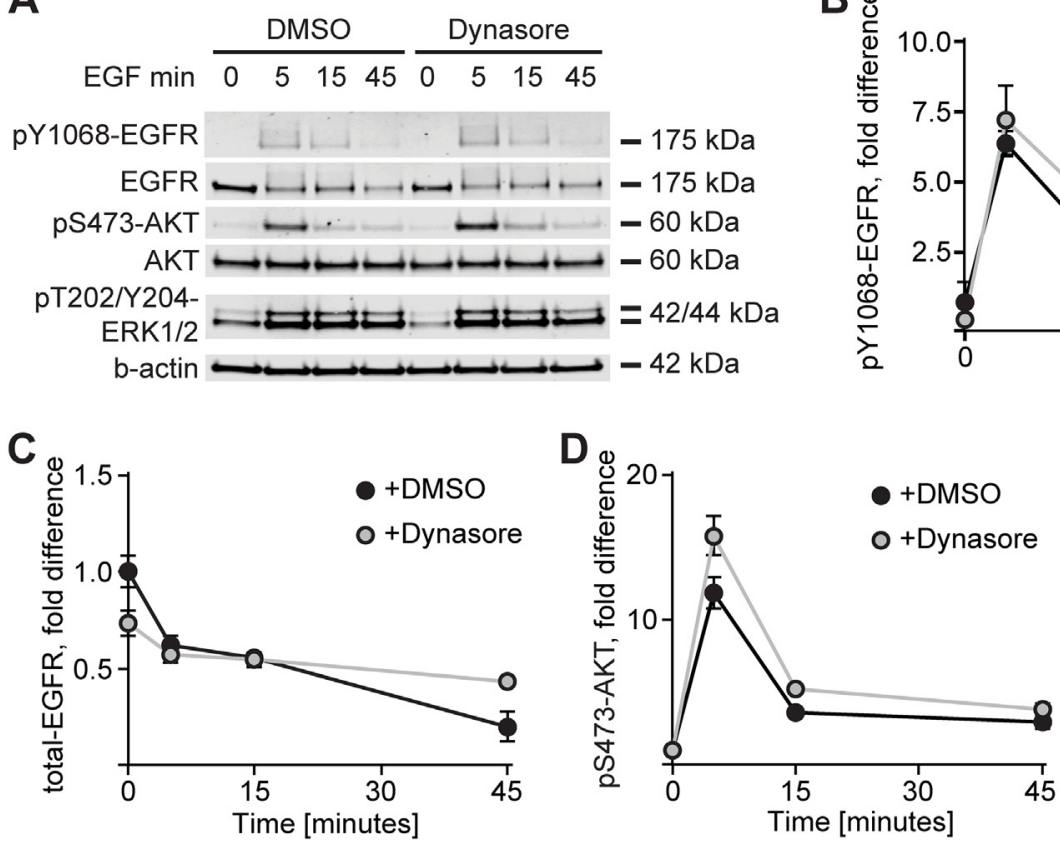

Time [minutes]
B 。

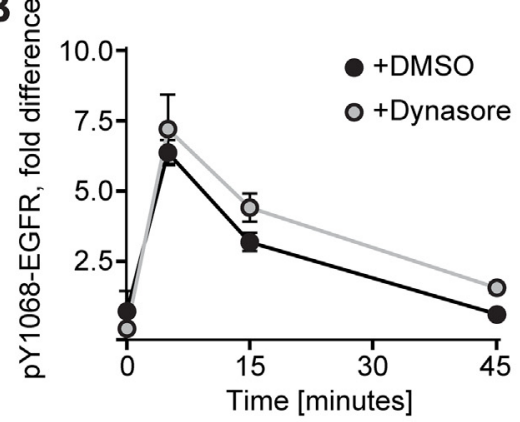

E

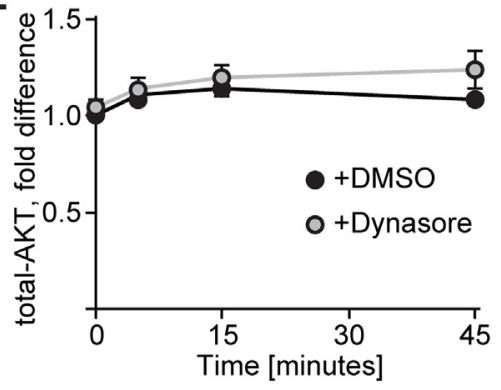

F

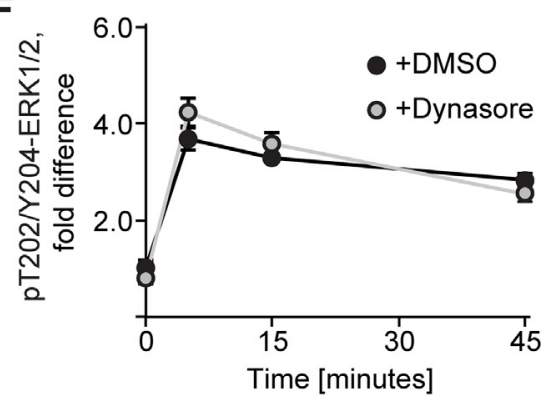

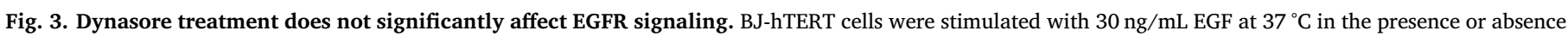

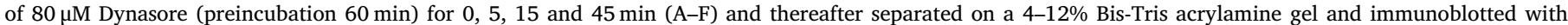

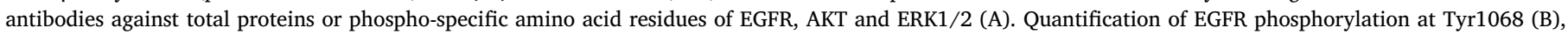

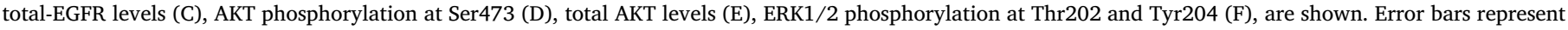
standard error of the mean ( $n=3$ for all experiments).

coated pits and subsequent internalization of the receptor to endosomal compartments, in response to PDGF-BB treatment.

\subsection{PDGFR- $\beta$ activation is independent of internalization}

To confirm that PDGFR- $\beta$ can be activated without internalization, we also performed kinetic studies on ice, i.e. a condition during which internalization is inhibited. For cells treated with PDGF-BB on ice, we saw a progressive increase by time of PDGFR- $\beta$ phosphorylation at Tyr751, as compared to the bell-shaped curve normally seen at $37^{\circ} \mathrm{C}$ (Fig. 5A and B). The slower activation of PDGFR $\beta$ in cells kept on ice has been attributed to slower kinetics of receptor dimerization and clustering, as well as inhibition of receptor internalization, degradation and de-phosphorylation. As expected, PDGFR- $\beta$ degradation was impaired on ice in comparison to cells stimulated at $37^{\circ} \mathrm{C}$ (Fig. 5A,C). Furthermore, none of the investigated signaling pathways downstream of PDGFR- $\beta$ was activated after stimulation with PDGF-BB on ice (Fig. 5A,D,E,F). The inhibition of downstream signaling via PDGFR- $\beta$ by stimulating cells on ice is consistent with a similar inhibition in cells treated with Dynasore, which also blocks receptor internalization (Figs. 1A,E,G and 4A,B).

\subsection{Phosphatase inhibition can induce PDGFR- $\beta$ phosphorylation in the presence of dynamin inhibition}

To induce phosphorylation of PDGFR- $\beta$ in the absence of ligandinduced dimerization, we treated the cells with pervanadate, which is a phosphatase inhibitor (Fig. 6). Without Dynasore the expected hyperphosphorylation of PDGFR- $\beta$ at Tyr751 was evident after stimulation with PDGF-BB, pervanadate or a combination of both. After treatment with Dynasore, we could still observe a pervanadate-induced PDGFR- $\beta$ phosphorylation, albeit less than in DMSO treated control cells (Fig. 6A and B). Notably, PDGF-BB treatment did not increase receptor phosphorylation further. This suggests that Dynasore inhibits PDGF-BBmediated activation, but does not directly inhibit PDGFR- $\beta$ kinase activity. As expected, the levels of PDGFR- $\beta$ (Fig. 6A,C) and AKT (Fig. 6A,E) were not significantly affected by pervanadate or Dynasore treatment. The downstream kinases AKT and ERK1/2 were activated by pervanadate treatment; these activations were not affected by Dynasore treatment suggesting that the effect on PDGFR- $\beta$ activation is not due to general kinase inhibition by Dynasore, but instead linked to plasma membrane dynamics (Fig. 6A,D,F). In contrast, in response to $5 \mathrm{~min}$ PDGF-BB stimulation, Dynasore treatment significantly decreased activation of AKT (Figs. 1A,E and 6A,D), but not of ERK1/2 (Figs. 1A,G 

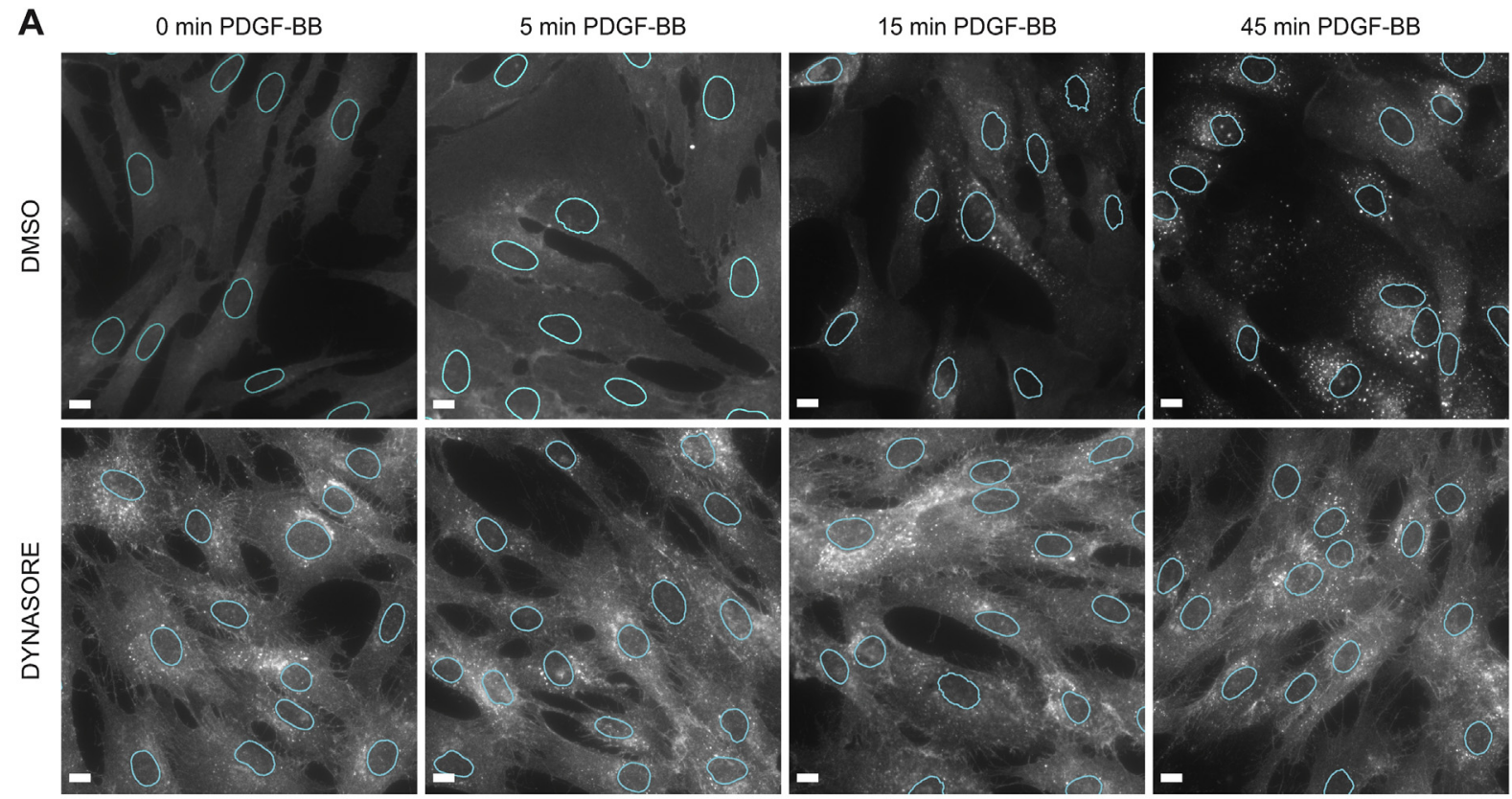

B

DMSO

DYNASORE
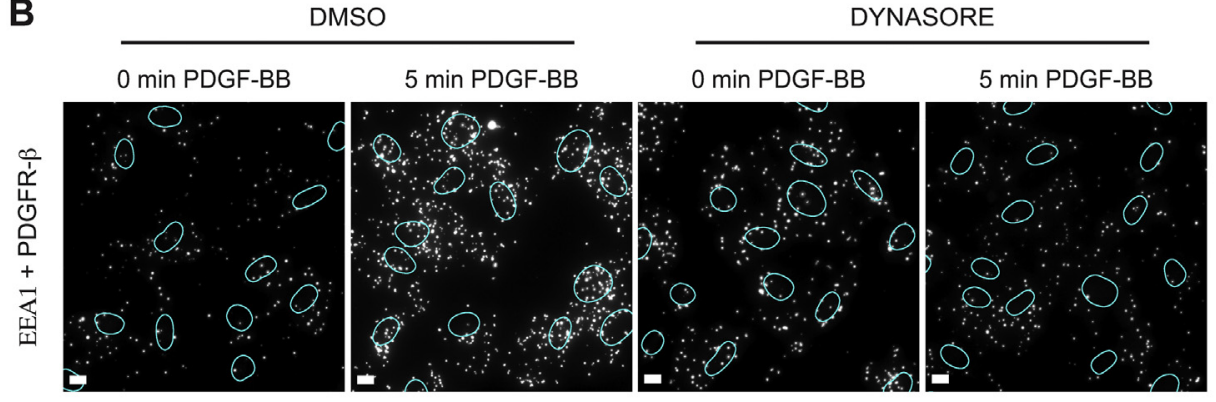

C - + DMso

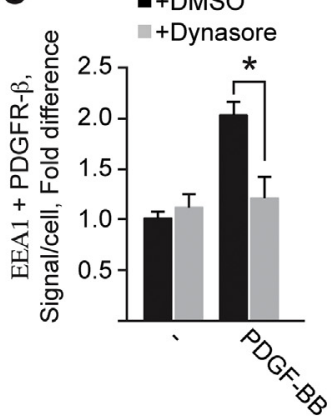

D

DMSO

DYNASORE
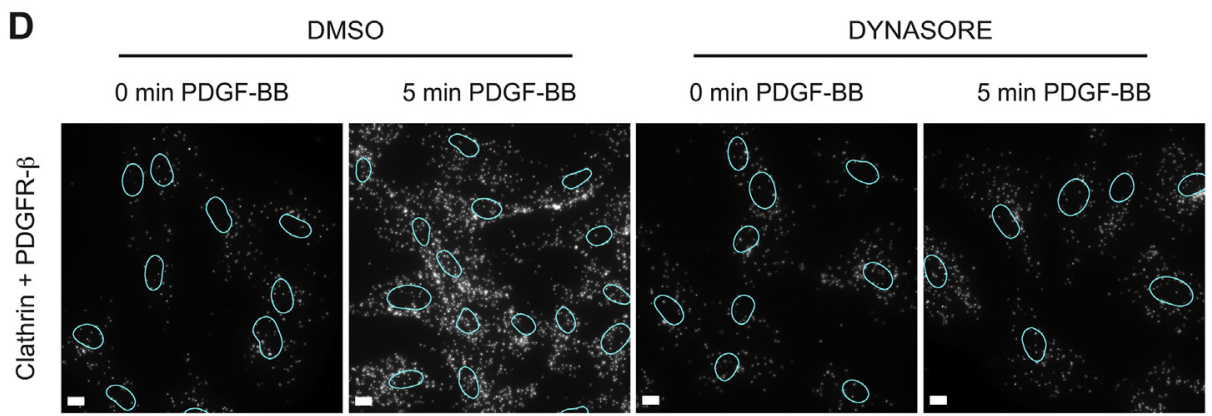

E

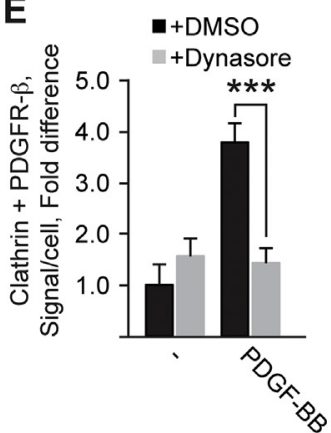

F

DMSO

DYNASORE

\section{G}
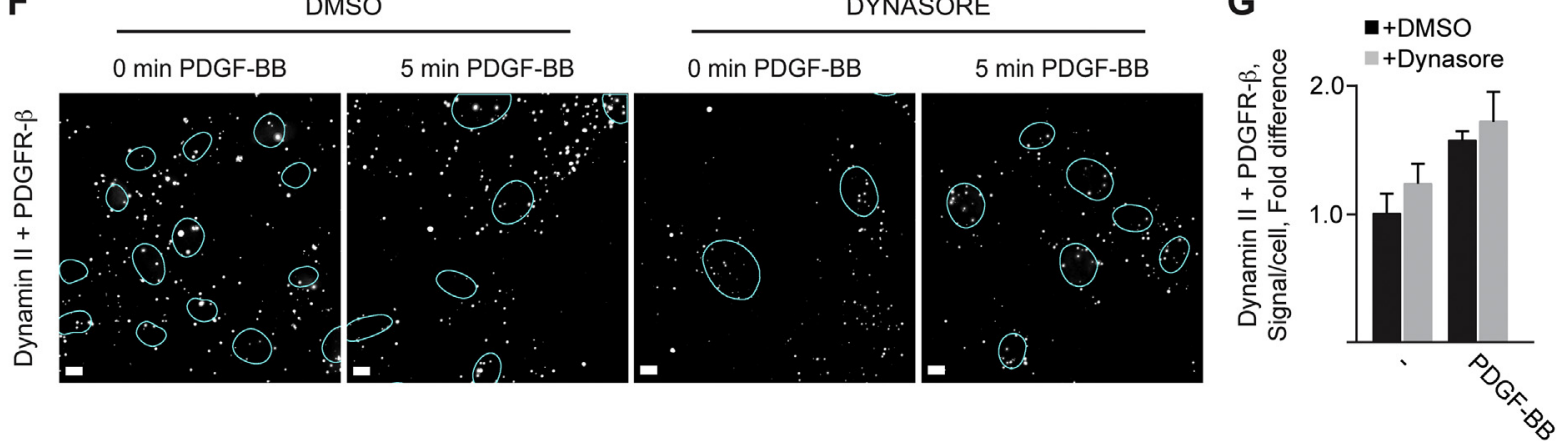

(caption on next page) 
Fig. 4. PDGFR- $\beta$ forms large structures upon Dynasore treatment, which also impairs PDGFR- $\beta$ internalization and recruitment to clathrin-coated pits. BJhTERT cells were stimulated with $50 \mathrm{ng} / \mathrm{mL}$ PDGF-BB at $37^{\circ} \mathrm{C}$ in the presence or absence of $80 \mu \mathrm{M}$ Dynasore (preincubation 60 min for immunostaining and $100 \mathrm{~min}$ for PLA) for $0,5,15$ and 45 min (immunostaining) or 0 and 5 min (PLA). The cells were thereafter investigated by immunostaining (A) or PLA (B-G). PDGFR- $\beta$ localization on early endosomes was visualized by antibodies against EEA1 and PDGFR- $\beta$ (B; quantified in C). PDGFR- $\beta$ recruitment to Clathrin-coated pits was visualized by antibodies against Clathrin and PDGFR- $\beta$ (D; quantified in E). PDGFR- $\beta$ association to Dynamin 2 was visualized by Dynamin $2+$ PDGFR- $\beta$ (F; quantified in G). The nuclei are outlined by a turquoise line. Error bars represent standard error of the mean (Scale bar $=10 \mu \mathrm{m}, n \geq 4$ for all experiments, except for the immunostaining where $n=3$ ), $*=p<0.05, * * *=p<0.005$.

and 6A,F). Collectively, these observations suggest that PDGF-BB-induced activation is abolished by Dynasore treatment, but not PDGFR- $\beta$ phosphorylation induced by pervanadate treatment, which is independent of ligand-induced receptor dimerization.

\subsection{Dynamin inhibitors impairs ligand-dependent PDGFR- $\beta$ dimerization}

Based on the results of the pervanadate experiment (Fig. 6), we next investigated if the effect of Dynasore could be attributed to a defect in ligand-induced receptor dimerization. To this end, we stimulated cells with PDGF-BB in the presence or absence of Dynasore followed by incubation on ice with the short plasma membrane impermeant cross-
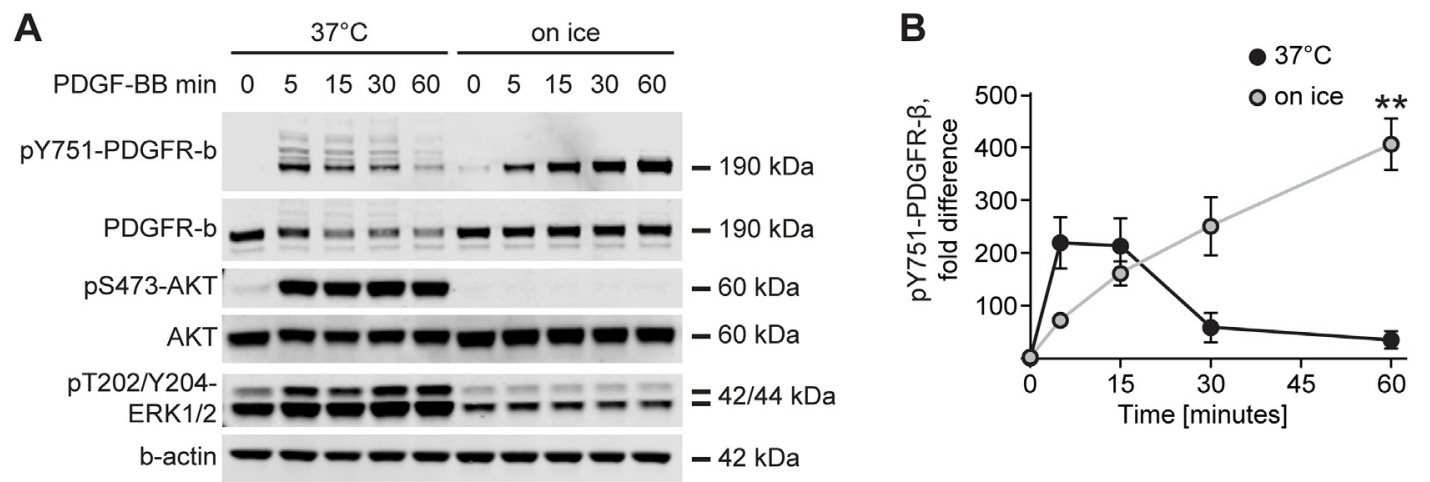

C

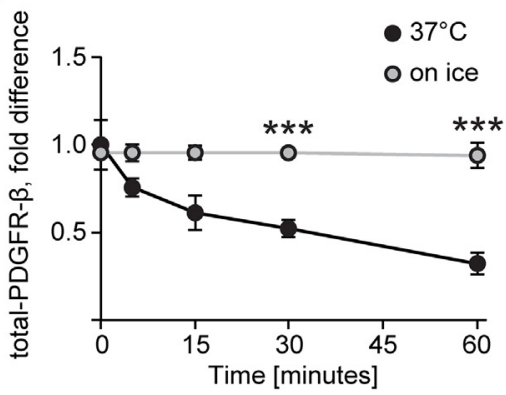

D
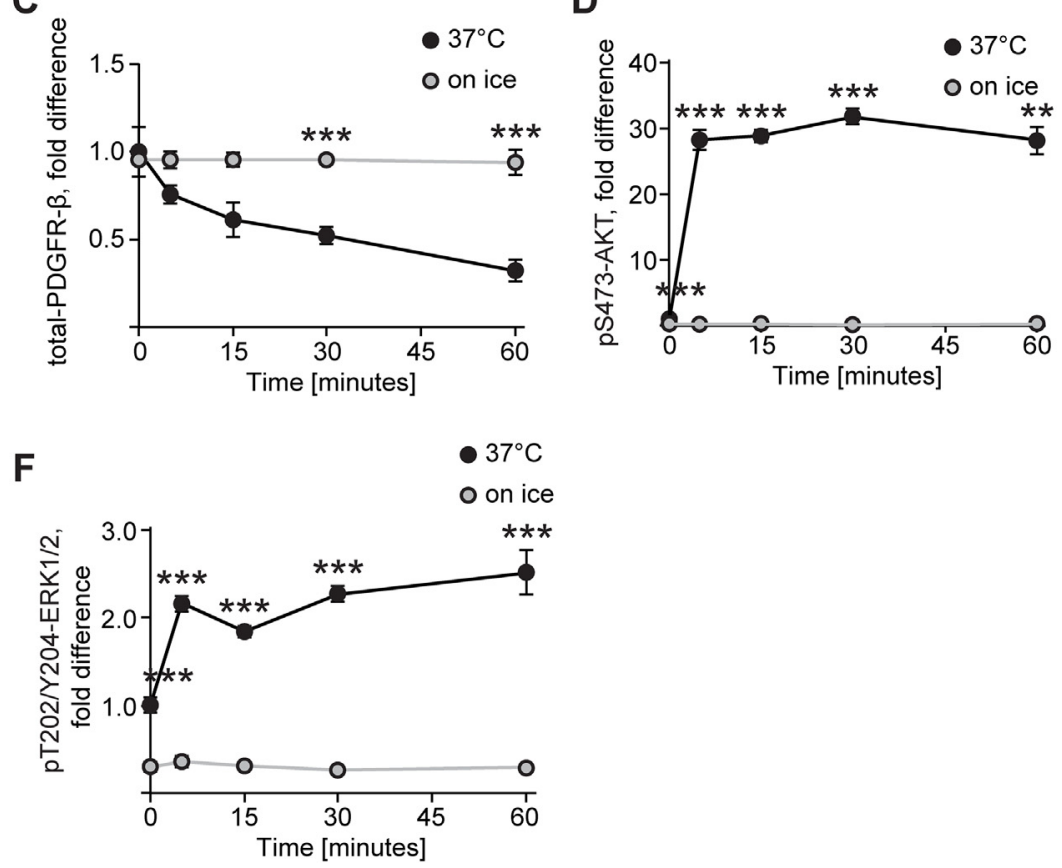

E linker BS3. Low temperature inhibits internalization from the plasma membrane; thus, only proteins at the plasma membrane will be crosslinked. PDGF-BB stimulation led to dimerization of PDGFR- $\beta$ only in the absence of Dynasore (Fig. 7A and B, dimerized receptor indicated by arrows); the total amount of receptor in the cells did not change significantly. Furthermore, the dimerized receptors were phosphorylated on Tyr751 (Fig. 7A,C), consistent with the notion that the band represents dimerized and phosphorylated PDGFR- $\beta$. The total PDGF-BBinduced phosphorylation of PDGFR- $\beta$ was inhibited by Dynasore treatment. In contrast, EGFR dimerization was unaffected by Dynasore treatment (Fig. 7D and E, dimerized receptor indicated by arrows). Next, we repeated the dimerization assay using cells treated with siRNA

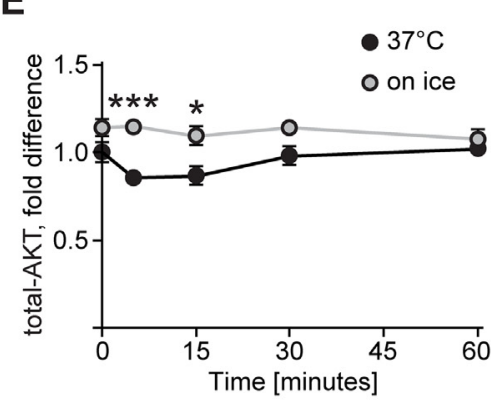

Fig. 5. PDGFR- $\beta$ activation, but not downstream signaling, occurs at $0^{\circ} \mathrm{C}$. BJ-hTERT cells were stimulated with $50 \mathrm{ng} / \mathrm{mL}$ PDGF-BB at $37^{\circ} \mathrm{C}$ or on ice for $0,5,15$, 30 and $60 \mathrm{~min}(\mathrm{~A}-\mathrm{F})$ and thereafter separated on a $4-12 \%$ Bis-Tris acrylamine gel and immunoblotted with antibodies against total proteins or phospho-specific amino acid residues of PDGFR- $\beta$, AKT and ERK1/2 (A). Quantification of PDGFR- $\beta$ phosphorylation at Tyr751 (B), total-PDGFR- $\beta$ levels (C), AKT phosphorylation at Ser473 (D), total AKT levels (E), ERK1/2 phosphorylation at Thr202 and Tyr204 (F), are shown. Error bars represent standard error of the mean $(n=3$ for all experiments), ${ }^{*}=\mathrm{p}<0.05,{ }^{* *}=\mathrm{p}<0.01,{ }^{* * *}=\mathrm{p}<0.005$. 

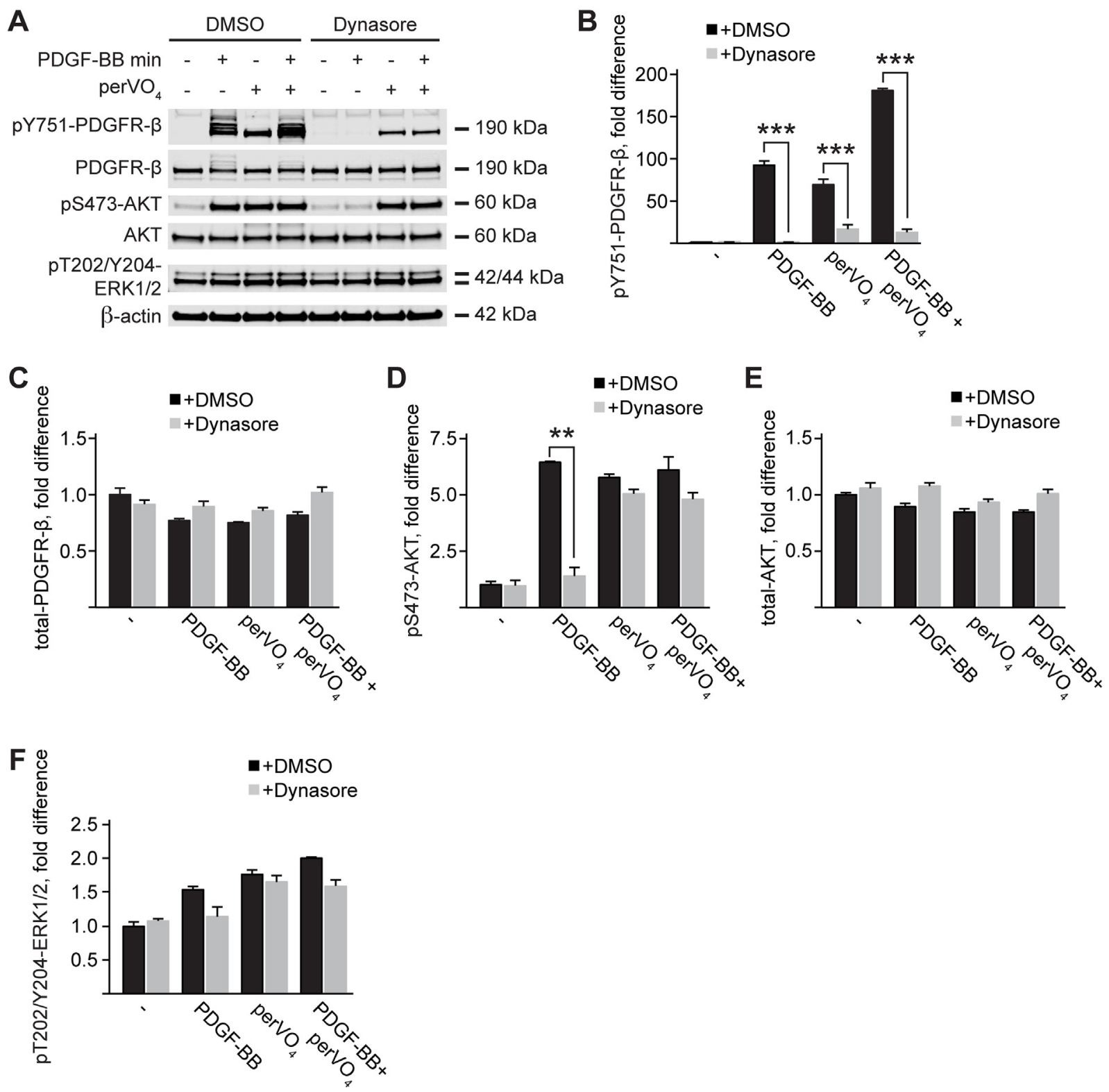

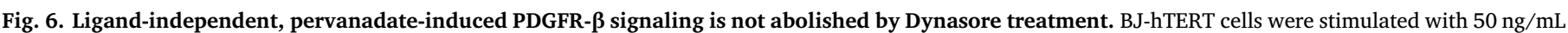

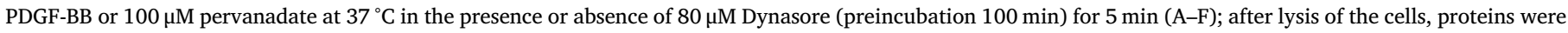

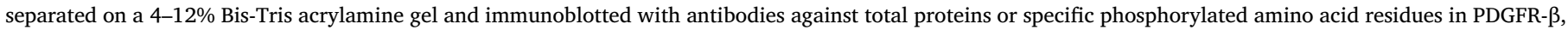

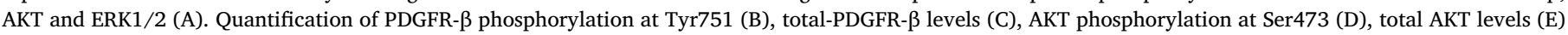

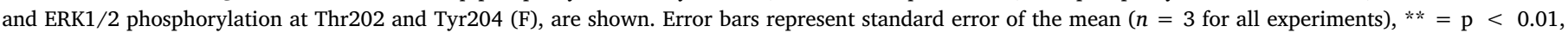
$* * *=\mathrm{p}<0.005$.

targeting Dynamin II. Knockdown of Dynamin II had a minor but significant effect on the amount of dimerized and phosphorylated PDGFR$\beta$, compared to Dynasore treatment (Suppl. Fig. 1; dimerized receptor indicated by arrows).

\section{Discussion}

In the present study, we show that Dynasore inhibits both internalization of PDGFR- $\beta$ and its dimerization and activation (Figs. 1, 2, 4 and 7). Furthermore, we corroborated this by showing that another dynamin inhibitor, Dyngo-4a, has the same effect on PDGFR- $\beta$ activation (Fig. 1). In contrast, Dynasore appears not to affect dimerization and activation of EGFR (Figs. 3 and 7). A possible explanation for this difference is that whereas PDGFR- $\beta$ preferentially undergoes clathrinmediated internalization, EGFR can also be internalized via other routes, depending on which EGFRs that are heterodimerized and which co-receptors that are available [3,21].

Dynamin II has a well-established role in the invagination and stabilization of clathrin-coated pits, so our finding that dynamin inhibitors halted PDGFR- $\beta$ internalization is not surprising (Fig. 4). However, our finding that Dynasore also impeded ligand-induced dimerization and activation of PDGFR- $\beta$ suggests a wider function for Dynamin II (Fig. 7). The exact mechanism whereby Dynasore inhibited PDGFR- $\beta$ dimerization is not known; it is possible that Dynamin II promotes receptor clustering in clathrin-coated pits, which may be a prerequisite for efficient ligand-induced PDGFR- $\beta$ dimerization.

As an attempt to corroborate our dynamin inhibitor results, we used siRNA-mediated knockdown of Dynamin II, however, only a minor, but significant, decrease in PDGFR- $\beta$ phosphorylation could be detected after siRNA treatment. Moreover, Jastrzebski et al. recently reported 
A

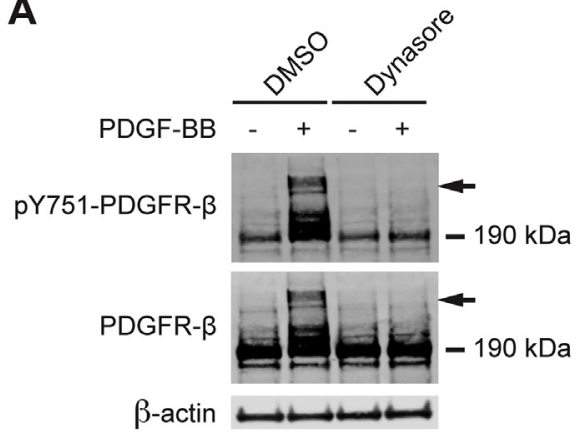

B

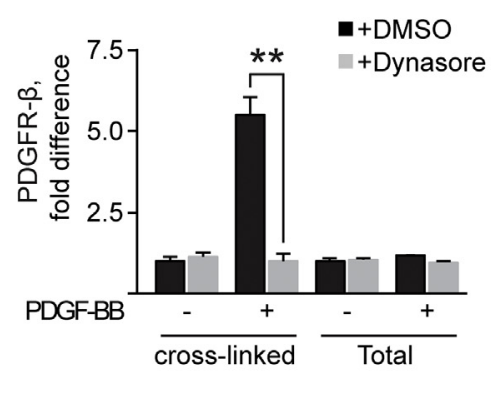

C

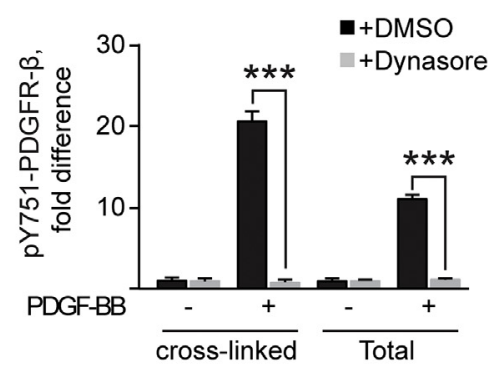

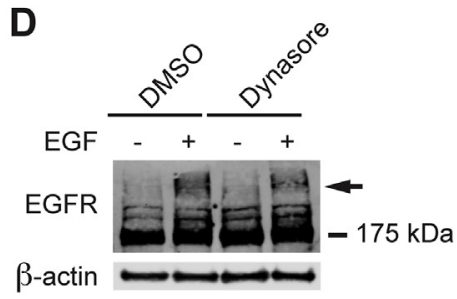

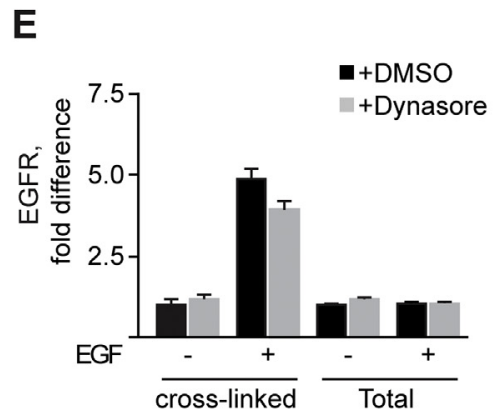

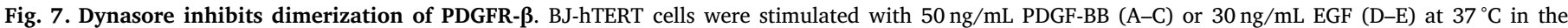

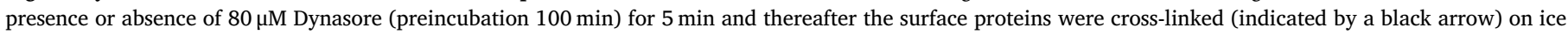

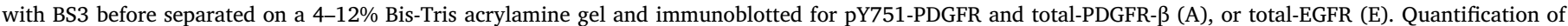

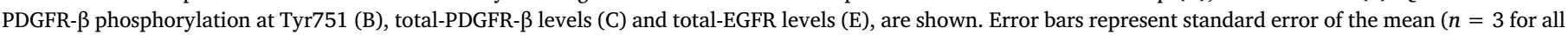
experiments), $* *=p<0.01, * * *=p<0.005$.

only a mild and non-significant effect on PDGFR- $\beta$ phosphorylation and downstream signaling after inhibition of internalization in CCD-1070SK skin fibroblasts, using siRNA against the clathrin scaffold protein AP2, heavy chain of clathrin or Dynamin II [22]. Their observations differ from our findings, using BJ-hTERT fibroblasts, since we found a decreased PDGFR- $\beta$ phosphorylation in response to siRNA targeting Dynamin II, and a complete inhibition of PDGFR- $\beta$ signaling, internalization and degradation in response to Dynasore or Dyngo-4a (Figs. 1, 2 and 4). It has been reported that even low levels of Dynamin II are able to sustain normal function [14,23], in contrast, Dynasore inhibits all dynamin II molecules. This may explain the limited effect observed with Dynamin II siRNA-mediated silencing, compared to Dynasore treatment, since residual Dynamin II may be sufficient to maintain functionality.

In another study, it was shown that shRNA knockdown of Dynamin II in glioma cells greatly impaired signaling downstream of PDGFR- $\alpha$, however, no drastic effect on PDGFR- $\alpha$ phosphorylation was seen [24]. It is possible that shRNA might not give a complete abolishment of Dynamin II protein levels in the cells, thus leaving some Dynamin II to maintain some functionality. It is notable that signaling via PDGFR- $\alpha$, which is structurally similar to PDGFR- $\beta$, was also found to be perturbed by inhibition of Dynamin II.

In contrast to our observations, Sadowski et al. saw no effect on PDGFR- $\beta$ signaling upon Dynasore or Dyngo-4a treatment [23]. The reason for the differences in findings remain to be elucidated. Possible explanations include use of different cell lines and conditions. For example, Dynasore and Dyngo-4a both bind to and are inactivated by BSA [13]. Thus, the amount of BSA they used in the culture medium during the experiments could affect the results. Moreover, Basagiannis et al. reported that vascular endothelial growth factor receptor 2 (VEGFR2) signaling and internalization was only marginally affected by Dynasore treatment [25]. Together with our finding that EGFR signaling was not affected by Dynasore treatment, this may illustrate that different members of the RTK family exhibit differences in dependency of
Dynamin for receptor activation upon ligand-stimulation.

PDGFR- $\beta$ was found to localize into aberrant structures at the plasma membrane upon Dynasore treatment (Fig. 4). These structures were not affected by addition of PDGF-BB and could represent a receptor pool that has been abnormally relocated to a plasma membrane subdomain where it is unavailable for activation. This notion is strengthened by the finding that Dynasore inhibited PDGFR- $\beta$ localization in EEA1-coated early endosomes, as well as to clathrin-coated pits (Fig. 4). In these Dynasore-induced structures, PDGFR- $\beta$ can be activated in a ligand- and dimerization-independent manner by inhibition of phosphatases by pervanadate showing that Dynasore does not directly inhibit the PDGFR- $\beta$ enzymatic activity (Fig. 6). However, phosphorylation of PDGFR- $\beta$ could not be further enhanced by PDGF$\mathrm{BB}$ stimulation in the presence of Dynasore.

In conclusion, we show that Dynamin inhibitors impedes ligandinduced dimerization and activation of PDGFR- $\beta$, as well as its internalization, suggesting that Dynamin II might be involved in two steps in PDGFR- $\beta$ signaling. The observation that dynamin inhibitors do not affect PDGFR and EGFR signaling equally opens up an avenue of new druggable targets that affects RTK signaling in a differential manner.

\section{Conflicts of interest}

No competing interests declared.

\section{Acknowledgments}

The authors thank Olink bioscience (Uppsala, Sweden) for providing the Duolink reagents and Carl-Henrik Heldin (Uppsala University, Sweden) for valuable comments and discussions.

\section{Appendix A. Supplementary data}

Supplementary data to this article can be found online at https:// 
doi.org/10.1016/j.yexcr.2019.04.004.

\section{Funding}

This study has been funded by grants from, the Swedish Foundation for Strategic Research, the Swedish Research Council, Swedish Cancer Society (CAN 2018/425 to JL) and P. O. Zetterlings Foundation (JH).

\section{References}

[1] C.H. Heldin, B. Lu, R. Evans, J.S. Gutkind, Signals and receptors, Cold Spring Harbor Perspect. Biol. 8 (2016) a005900.

[2] C.H. Heldin, J. Lennartsson, B. Westermark, Involvement of platelet-derived growth factor ligands and receptors in tumorigenesis, J. Intern. Med. 283 (2018) 16-44.

[3] S. Mukherjee, M. Tessema, A. Wandinger-Ness, Vesicular trafficking of tyrosine kinase receptors and associated proteins in the regulation of signaling and vascular function, Circ. Res. 98 (2006) 743-756.

[4] K. Gaengel, C. Betsholtz, Endocytosis regulates VEGF signalling during angiogenesis, Nat. Cell Biol. 15 (2013) 233-235.

[5] A. Sorkin, M. von Zastrow, Endocytosis and signalling: intertwining molecular networks, Nat. Rev. Mol. Cell Biol. 10 (2009) 609-622.

[6] J.M. Haugh, T. Meyer, Active EGF receptors have limited access to PtdIns $(4,5) \mathrm{P}(2)$ in endosomes: implications for phospholipase C and PI 3-kinase signaling, J. Cell Sci. 115 (2002) 303-310.

[7] S.A. Rodt, K. Ahlen, A. Berg, K. Rubin, R.K. Reed, A novel physiological function for platelet-derived growth factor-BB in rat dermis, J. Physiol. 495 (Pt 1) (1996) 193-200.

[8] R. Ramachandran, S.L. Schmid, The dynamin superfamily, Curr. Biol. 28 (2018) R411-R416.

[9] E. Macia, M. Ehrlich, R. Massol, E. Boucrot, C. Brunner, T. Kirchhausen, Dynasore, a cell-permeable inhibitor of dynamin, Dev. Cell 10 (2006) 839-850.

[10] B. Antonny, C. Burd, P. De Camilli, E. Chen, O. Daumke, K. Faelber, M. Ford, V.A. Frolov, A. Frost, J.E. Hinshaw, T. Kirchhausen, M.M. Kozlov, M. Lenz, H.H. Low, H. McMahon, C. Merrifield, T.D. Pollard, P.J. Robinson, A. Roux, S. Schmid, Membrane fission by dynamin: what we know and what we need to know, EMBO J. 35 (21) (2016 Nov 2) 2270-2284.

[11] S.M. Ferguson, P. De Camilli, Dynamin, a membrane-remodelling GTPase, Nat. Rev. Mol. Cell Biol. 13 (2012) 75-88.

[12] J.E. Hinshaw, Dynamin and its role in membrane fission, Annu. Rev. Cell Dev. Biol. 16 (2000) 483-519.

[13] A. McCluskey, J.A. Daniel, G. Hadzic, N. Chau, E.L. Clayton, A. Mariana, A. Whiting, N.N. Gorgani, J. Lloyd, A. Quan, L. Moshkanbaryans, S. Krishnan,
S. Perera, M. Chircop, L. von Kleist, A.B. McGeachie, M.T. Howes, R.G. Parton, M. Campbell, J.A. Sakoff, X. Wang, J.Y. Sun, M.J. Robertson, F.M. Deane, T.H. Nguyen, F.A. Meunier, M.A. Cousin, P.J. Robinson, Building a better dynasore: the dyngo compounds potently inhibit dynamin and endocytosis, Traffic 14 (2013) $1272-1289$.

[14] R.J. Park, H. Shen, L. Liu, X. Liu, S.M. Ferguson, P. De Camilli, Dynamin triple knockout cells reveal off target effects of commonly used dynamin inhibitors, J. Cell Sci. 126 (2013) 5305-5312.

[15] J. Heldin, P. O'Callaghan, R. Hernandez Vera, P.F. Fuchs, P. Gerwins, J. Kreuger, FGD5 sustains vascular endothelial growth factor A (VEGFA) signaling through inhibition of proteasome-mediated VEGF receptor 2 degradation, Cell. Signal. 40 (2017) 125-132.

[16] K. Grannas, L. Arngarden, P. Lonn, M. Mazurkiewicz, A. Blokzijl, A. Zieba, O. Soderberg, Crosstalk between Hippo and TGFbeta: subcellular localization of YAP/TAZ/smad complexes, J. Mol. Biol. 427 (2015) 3407-3415.

[17] A.E. Carpenter, T.R. Jones, M.R. Lamprecht, C. Clarke, I.H. Kang, O. Friman, D.A. Guertin, J.H. Chang, R.A. Lindquist, J. Moffat, P. Golland, D.M. Sabatini, CellProfiler: image analysis software for identifying and quantifying cell phenotypes, Genome Biol. 7 (2006) R100.

[18] M. Baumdick, Y. Bruggemann, M. Schmick, G. Xouri, O. Sabet, L. Davis, J.W. Chin, P.I. Bastiaens, EGF-dependent re-routing of vesicular recycling switches spontaneous phosphorylation suppression to EGFR signaling, Elife 4 (2015).

[19] O. Soderberg, M. Gullberg, M. Jarvius, K. Ridderstrale, K.J. Leuchowius, J. Jarvius, K. Wester, P. Hydbring, F. Bahram, L.G. Larsson, U. Landegren, Direct observation of individual endogenous protein complexes in situ by proximity ligation, Nat. Methods 3 (2006) 995-1000.

[20] B. Koos, L. Andersson, C.M. Clausson, K. Grannas, A. Klaesson, G. Cane, O. Soderberg, Analysis of protein interactions in situ by proximity ligation assays, Curr. Top. Microbiol. Immunol. 377 (2014) 111-126.

[21] K. Sandvig, S. Kavaliauskiene, T. Skotland, Clathrin-independent endocytosis: an increasing degree of complexity, Histochem. Cell Biol. 150 (2) (2018 Aug) 107-118, https://doi.org/10.1007/s00418-018-1678-5 Epub 2018 May 17.

[22] K. Jastrzebski, D. Zdzalik-Bielecka, A. Maminska, Y. Kalaidzidis, C. Hellberg, M. Miaczynska, Multiple routes of endocytic internalization of PDGFRbeta contribute to PDGF-induced STAT3 signaling, J. Cell Sci. 130 (3) (2017 Feb 1) 577-589.

[23] L. Sadowski, K. Jastrzebski, Y. Kalaidzidis, C.H. Heldin, C. Hellberg, M. Miaczynska, Dynamin inhibitors impair endocytosis and mitogenic signaling of PDGF, Traffic 14 (2013) 725-736.

[24] H. Feng, K.W. Liu, P. Guo, P. Zhang, T. Cheng, M.A. McNiven, G.R. Johnson, B. Hu, S.Y. Cheng, Dynamin 2 mediates PDGFRalpha-SHP-2-promoted glioblastoma growth and invasion, Oncogene 31 (2012) 2691-2702.

[25] D. Basagiannis, S. Zografou, K. Galanopoulou, S. Christoforidis, Dynasore impairs VEGFR2 signalling in an endocytosis-independent manner, Sci. Rep. 7 (2017) 45035 . 